\title{
Supporting Information for Beach sands along the California coast are diffuse sources of fecal bacteria to coastal waters
}

\author{
Kevan M. Yamahara, Blythe A. Layton, Alyson E. Santoro, Alexandria B. Boehm* \\ Department of Civil and Environmental Engineering, Environmental and Water Studies \\ Stanford University, Stanford, California 94305-4020
}

April 16, 2007

A manuscript for

Environmental Science and Technology

\footnotetext{
${ }^{*}$ Corresponding author: Tel: (650) 724-9128, Fax: (650) 725-3164, E-mail: aboehm@stanford.edu
} 


\section{Methods}

\subsection{CA Beach Sand Survey}

\subsubsection{Enumeration of ENT and EC in beach sands}

Between 15-25 mL of sand were added to a conical tube and weighed. Forty $\mathrm{mL}$ of sterile milliQ water were added to the conical tube. The mixture was shaken by hand for two minutes and allowed to settle for $30 \mathrm{~s}$. Supernatant was withdrawn and analyzed by membrane filtration on mEI (ENT) and MI (EC) agar. On average the lower and upper limits of detection were 12 and 5951 colony forming units (CFU)/100 g dry weight, respectively. Densities are reported as CFU per $100 \mathrm{~g}$ dry weight of sands.

\subsubsection{Salmonellae enumeration in sand}

Sand was pre-weighed and added to tryptic soy broth (TSB) and incubated at $37^{\circ} \mathrm{C}$ overnight. A matrix control was prepared by adding a loopful of Salmonella enterica serovar Typhimurium LT2 to a sand sample and then adding the inoculated sand to TSB. Positive and negative controls were prepared with Salmonella enterica serovar Typhimurium LT2 and Enterococcus faecium (ATCC 19434), respectively. 30 $\mu \mathrm{l}$ of TSB enrichment was dropped onto modified semi-solid Rappaport-Vassiliadis (MSRV) medium and incubated at $42^{\circ} \mathrm{C}$ for $24 \mathrm{~h}$. Motile organisms were picked, streaked on xylose lysine deoxycholate agar, and incubated at $37^{\circ} \mathrm{C}$ for 24 hours. Colonies displaying typical salmonellae morphology were picked and subjected to biochemical assays: lysine iron agar, triple sugar iron agar, and urea broth. Presumptive positives were confirmed using a polymerase chain reaction (PCR) assay that targets the salmonellae-specific invA gene. Primers and conditions for the PCR reactions are given in Malorny et al. (1). PCR products were visualized on a $1.5 \%$ agarose gel stained with ethidium bromide. Positive and negative PCR, and extraction controls were run in conjunction with unknowns.

\subsubsection{Moisture content, organic carbon content, and percent fines measured in CA sand survey}

The percent moisture content by mass $\left(\theta_{m}\right)$ of each sand sample was determined by drying pre-weighed sand at $110^{\circ} \mathrm{C}$ for $24 \mathrm{~h}$. $\theta_{m}$ was used to normalize all bacterial densities to $100 \mathrm{~g}$ dry sand. The percent organic carbon content by mass $\left(C_{m}\right)$ was estimated for each sand sample using loss on ignition (2). Dry sand was ashed at $550^{\circ} \mathrm{C}$ for 5 hours and cooled in a dessicator. The error associated with triplicate measurements of $C_{m}$ was approximately $0.1 \%$.

Grain size of each sand sample was determined by sieving. The percent mass of sand retained on and passing through \#35 $(0.5 \mathrm{~mm})$, \#60 $(0.25 \mathrm{~mm})$, and \#120 $(0.125 \mathrm{~mm})$ sieves was calculated after shaking for $5 \mathrm{~min}$ at $4000 \mathrm{rpm}$. Percent fines was determined by adding the mass of sand retained and passing through the \#120 sieve and dividing by the total mass analyzed.

\subsection{Lovers Point Study}

\subsubsection{Column experiment}

A column experiment was conducted to determine if seawater mobilizes ENT associated with Lovers Point (LP) beach sand. Exposed sand from above the high tide line naturally contaminated with ENT at a density of $2600 \mathrm{CFU} / 100 \mathrm{~g}$ was collected from LP, and seawater from adjacent Monterey Bay. Sand and seawater were stored at $4^{\circ} \mathrm{C}$ for $12 \mathrm{~h}$ prior to the experiment. Sand was packed into a $3.5 \mathrm{~cm}$ diameter 10 $\mathrm{cm}$ long glass chromatography column to a porosity of $\phi \approx 0.29$. Seawater was $0.2 \mu \mathrm{m}$ filter sterilized and pumped through the column at a rate of $1.5 \mathrm{~mL} \mathrm{~min}^{-1}$. No effort was made to maintain specific saturation conditions. Rather, we sought to mimic the wetting of sand by seawater as it might occur in the field. Fifty $7.7 \mathrm{~mL}$ fractions were collected using an automated fraction collector and analyzed for ENT within $6 \mathrm{~h}$ 
using EPA method 1600 (3). Results were displayed as concentration in fractions as a function of pore volume $V_{p}=Q t / V$ where $Q$ is the flow rate, $t$ is the time elapsed, and $V$ is the volume of pore space.

\subsubsection{Moisture content as measured during Lovers Point $24 \mathrm{hr}$ field study}

The moisture content of the exposed and submerge sands during the Lovers Point study was measured as follows. $\theta_{m}$ of the exposed sand samples was measured in situ using a soil moisture probe (ML2X, delta-T, Cambridge, UK). A calibration curve, relating voltage output to $\theta_{m}$ was created, following manufacturers directions. All submerged sand samples were saturated with $\theta_{m}=19 \%$. Sand temperature was measured using a digital thermometer.

\subsection{3 esp gene assay}

Membrane filters with ENT colonies were removed from mEI agar plates and placed in TSB for 4 to $6 \mathrm{~h}$ at $41^{\circ} \mathrm{C}$. DNAs were extracted from a $1 \mathrm{~mL}$ aliquot of enrichment using QIAamp DNA Mini Kit (Qiagen, Valencia, CA). PCR reactions containing $3 \mu \mathrm{l}$ template were run using the conditions, primers, and buffers described by Scott et al. (4), except we used Platinum Taq (Invitrogen, Eugene, OR). PCR products were run on a 1.5\% agarose gel and stained with SYBR Gold (Invitrogen, Eugene, OR). Positive and negative PCR and extraction controls were run in conjunction with unknowns.

\subsubsection{Human specific Bacteroides marker assay}

In February 2007, three $20 \mathrm{~g}$ (wet weight) sand samples were collected from above the high tide line and one $20 \mathrm{~g}$ (wet weight) sample from near the storm drain to assay for the human specific Bacteroides (HF) marker. DNAs were extracted from the sands using two different methods. (1) DNAs from $1 \mathrm{~g}$ of sand from near the storm drain and $1 \mathrm{~g}$ of sand from a single high tide sand sample were extracted using the FastDNA Spin Kit for soil (Qbiogene, Irvine, CA) with a final elution in $100 \mu \mathrm{L}$ of DNase-free water. (2) $20 \mathrm{~g}$ of sand from near the storm drain and $20 \mathrm{~g}$ of sand from near the high tide line were composited, and two $20 \mathrm{~g}$ sand samples from the high tide were composited. $100 \mathrm{~mL}$ of phosphate buffered saline (PBS) were added to the composited samples and shaken by hand for 2 min and allowed to settle for $30 \mathrm{~s}$. The eluants were vacuum filtered onto $45 \mathrm{~mm}$ diameter, $0.22 \mathrm{~m}$ pore size Durapore membrane filters (Millipore Corporation, Billerica, MA). DNAs were extracted from the filters as described in Santoro and Boehm (5) with a final elution in $100 \mu \mathrm{L}$ of DNase free water. DNAs were analyzed for the HF marker using methods outlined in Santoro and Boehm (5) using the HF183F/708R primer set. Ten-fold dilutions of all negative samples were also screened to test for the presence of inhibitors.

In March 2007, two-250 mL storm drain effluent samples and a single $1000 \mathrm{~mL}$ surf zone sample were assayed for the (HF) marker following methods given by Santoro and Boehm (5) using the HF183F/708R primer set.

\subsection{Statistical Analyses}

Non-parametric methods were chosen over parametric methods because neither FIB distributions nor their transformed distributions were normal (based on Lilliefors test of normality). Bacteria densities below the detection limit were assigned a value of one-half the detection limit and densities above the upper detection limit were assigned the upper limit of detection (assumed to correspond with 500 CFUs on a membrane). $\mathrm{N}$-way analyses of variance (ANOVAs) were used to assess the role beach and sand characteristics play in controlling the variability of ENT and EC in beach sand along the CA coast. The dependent variables for the N-way ANOVAs included (1) the ranked ENT and EC densities and (2) the presence/absence ENT and EC. Independent categorical variables included (1) the presence of a putative FIB source, (2) the presence of wave action, (3) quartile of developed land use, and (4) quartile of a "sand factor". A sand factor was extracted using principle component analysis from $C_{m}, \theta_{m}$, and percent fines data series and was necessary because these three factors were positively, significantly correlated to one another (Table S3). A high sand 
factor value indicated sand was high in percent fines, $C_{m}$, and $\theta_{m}$ (see paragraph). A type III ANOVA was used that allowed up to 2-way interaction terms. Terms were eliminated from the model one-by-one if they did not describe a significant percent of the variance of the dependent variable. All results and relationships were deemed significant if $p<0.05$.

\subsubsection{Sand Factor}

Sands high in percent fines tended to be high in organic carbon $\left(C_{m}\right)$ and moisture $\left(\theta_{m}\right)$. Pearson's correlation coefficients, $r_{p}$ between the three parameters were positive and significant $(p<0.05$, Table S3). Using SPSS, a single principle component was extracted from these three variables, hereafter termed sand factor. The sand factor accounts for $52 \%$ of the total variance in the three data series, and is highly correlated to the percent fines $(r=0.688), \theta_{m}(r=0.792)$, and $C_{m}(r=0.684)$. We can interpret a high value of the sand factor to indicate sand that is high in percent fines, $\theta_{m}$, and $C_{m}$.

\section{Results from Lovers Point Study}

\subsection{Inventory analysis of ENT in sand and water}

Assuming the concentration of $120 \mathrm{CFU} / 100 \mathrm{~mL}$ was representative of the Lover Point's (LP's) nearshore waters at 21:00 and was maintained in a triangular volume of water $2 \mathrm{~m}$ wide at the surface, $1 \mathrm{~m}$ deep at the most offshore location, and $100 \mathrm{~m}$ long in the along-beach direction $\left(V_{w}=10 \times 10^{7} \mathrm{~cm}^{3}\right)$, then $12 \times 10^{7}$ $\mathrm{CFU}$ entered the water column to produce the observed concentration. We estimate that approximately $187 \mathrm{CFU} / 100 \mathrm{~g}$ ENT were removed from the sand during the first flood tide from the data presented in Fig. S6B. The volume of sand $\left(V_{s}\right)$ that lost this ENT density is estimated to be $5 \mathrm{~cm}$ deep, $100 \mathrm{~m}$ long (the length of the entire cove), and $9 \mathrm{~m}$ wide (the width of the region of exposed sand submerged by the rising tide, Fig. S6A). Since $\rho_{b}=1.5 \mathrm{~g} \mathrm{~cm}^{-3}$ at LP, this implies that $12.6 \times 10^{7} \mathrm{CFU}$ were lost from the sand. This number is $105 \%$ the number we estimate are present in the nearshore waters of the beach. Despite the uncertainty in the values used to calculate $V_{w}$ and $V_{s}$, this calculation suggests the number of ENT in the water at 21:00 is not vastly different from the amount we approximate is lost from the sand.

\subsection{Box model of ENT in nearshore waters}

If we assume that ENT were seeded into a vertically well mixed water mass adjacent to the beach with volume $V_{w}$ at high tide $(t=0)$ resulting in a concentration $E N T_{o}$, then $E N T(t)$, the concentration of ENT in $V_{w}$, will decrease exponentially with time at a rate $(1 / \tau+k)$ where $\tau$ is residence time of water in $V_{w}$, and $k$ is the first order inactivation rate of ENT in seawater. We fit a line $(r=0.87, p<0.05)$ to $\ln \left(E N T(t) / E N T_{o}\right)$ where $E N T(t)$ is the time series of smoothed ENT densities and includes all data collected after 21:00 (when the spike in ENT density was observed), and $E N T_{o}$ is the ENT density at 21:00. The slope of this line $m=-0.0011 \mathrm{~min}^{-1}$, and is equal to $(1 / \tau+k)$. We estimate that $k$ is between $2 \times 10^{-4}$ and $5 \times 10^{-4} \mathrm{~min}^{-1}$ based on the compilation of $k$ as well as two measured values of $k$ in Monterey Bay seawater reported by Boehm et al. (6). This implies that the decline in ENT in the nearshore after it is seeded into the water column (Fig. 3) can be explained by first order decay and dilution if the residence time of water $\tau$ in the nearshore is between 18 and $26 \mathrm{~h}$. Although we did not measure $\tau$ during the study, we believe that $18-26 \mathrm{~h}$ is not unreasonable. Nearshore waters at this beach were extremely quiescent during the study. Floating wrack and foam along the beach were observed to move slowly over the $24 \mathrm{~h}$ study, but did not leave the study area, suggesting that the residence time of water adjacent to the beach face was on the order of a day.

\subsection{Human specific Bacteroides marker assay results}

We found the HF marker in 2 of 2 storm drain effluent samples, 1 of 1 nearshore water sample, and in sand from near the storm drain and the high tide line (Table S4). We employed two methods for DNA extraction from the sands. In one method, we extracted the DNA directly from $1 \mathrm{~g}$ of sand collected near 
the storm drain and $1 \mathrm{~g}$ of sand near the high tide line using a soil DNA extraction kit. Using this method, sand collected near the storm drain was positive for the HF marker, while sand near the high tide line was negative. A drawback of this DNA extraction method is that only a small mass of sand can be analyzed which could lead to a relatively high lower limit of detection.

In the other method, we eluted bacteria from two composited sand samples each composite with a total mass of $40 \mathrm{~g}$, in PBS. The eluant was subsequently filtered and DNAs subsequently extracted from the filter. The two composite samples include a composite of sand from near the storm drain and sand from near the high tide line, and a composite of two samples collected near the high tide line. Using this DNA extraction method, the composite of sands from near the high tide line was positive for the HF marker (after diluting 1:10 in DNase free water), while the sample containing sand from near the storm drain was negative for the HF marker (even after 1:10 dilution).

This preliminary exercise to detect the HF marker in sands points out both the potentially important role of inhibition and the inherent heterogeneity of the sand matrix. These two methods of DNA extraction for HF marker detection in beach sand should be further investigated. These results agree with results from the esp gene analysis human sewage appears to be impacting water and sand quality at LP. 


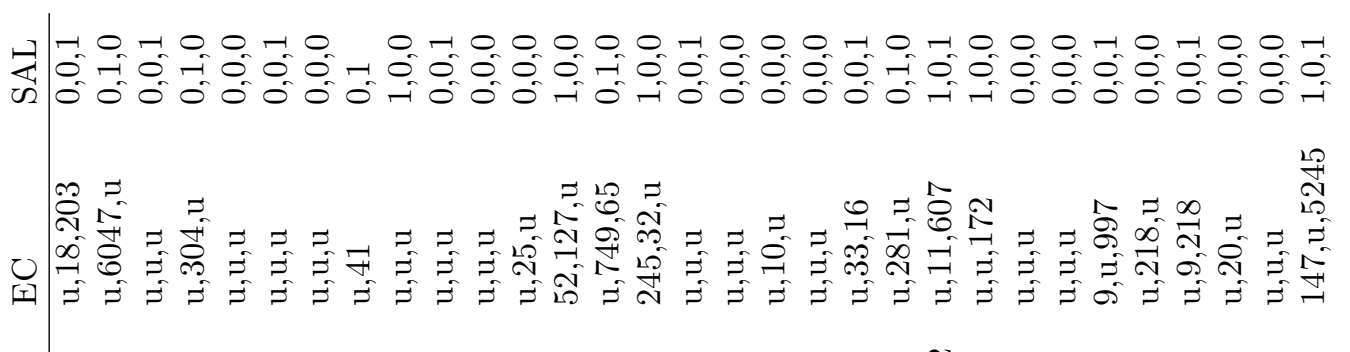

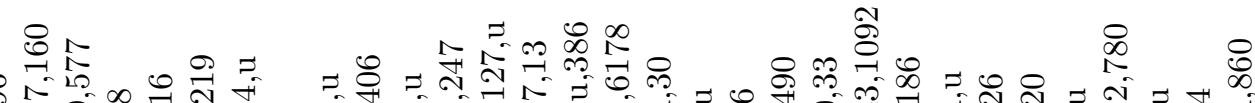

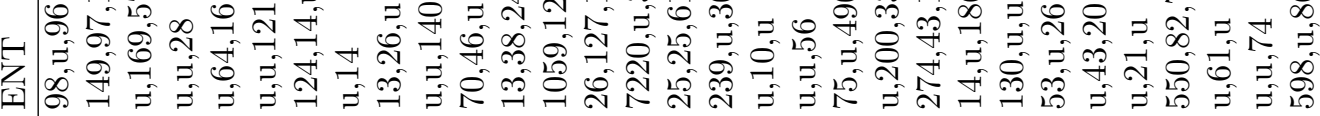

ศ เ

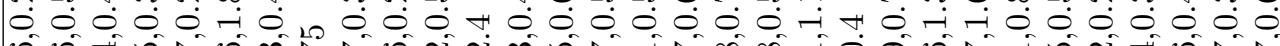
0 0 +

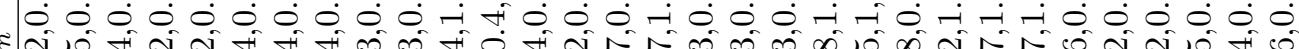

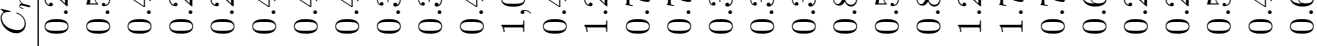

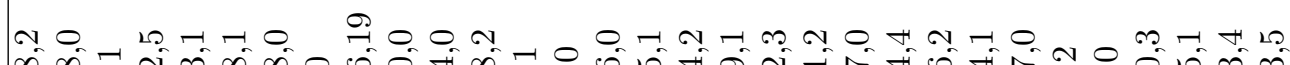

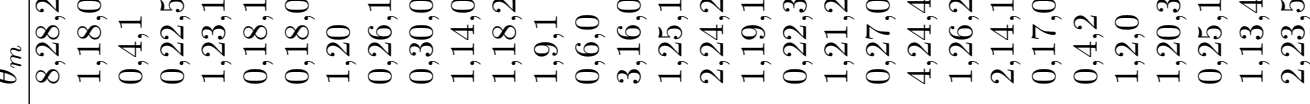

숭 च ถ⿻

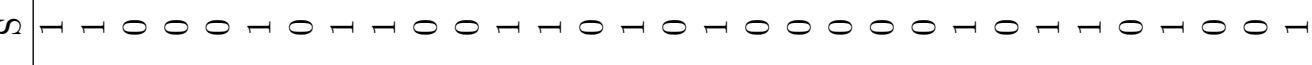

及

ค

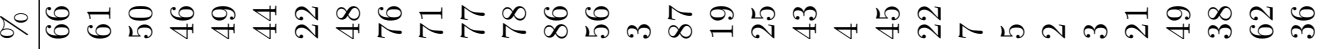

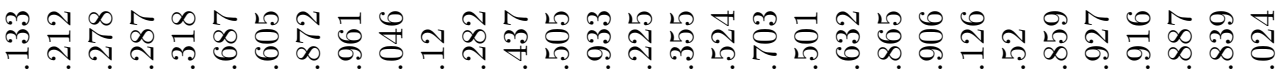
0

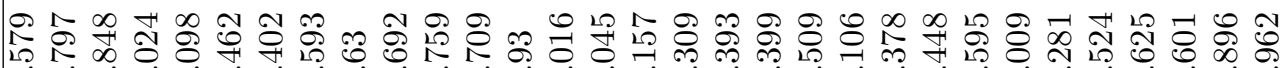
岃

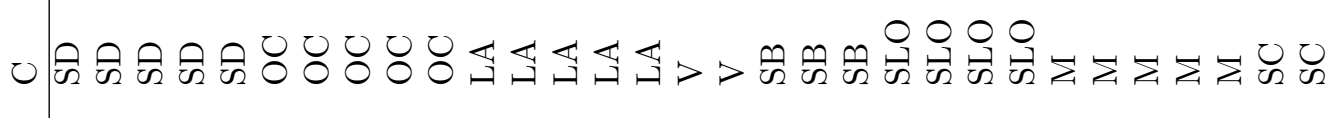

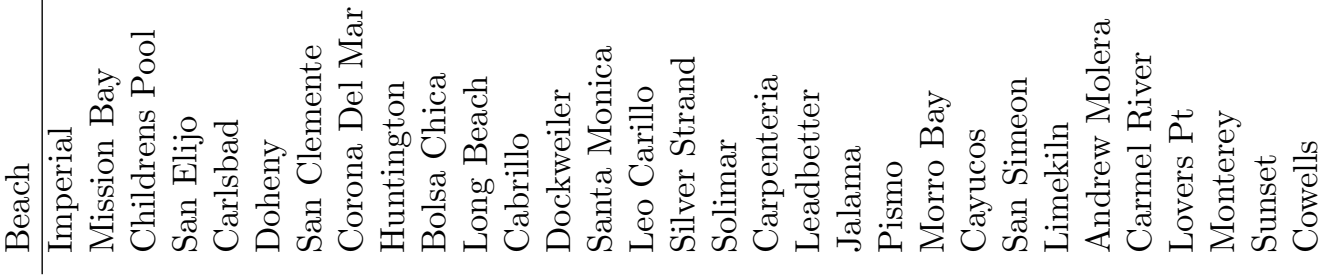


ำ

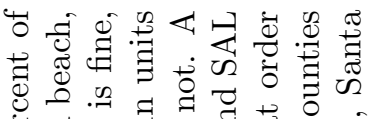

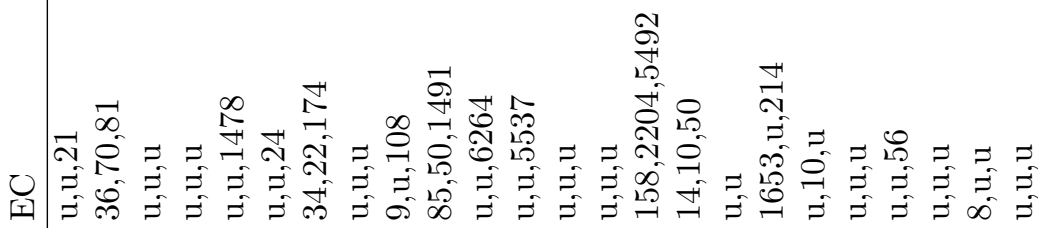

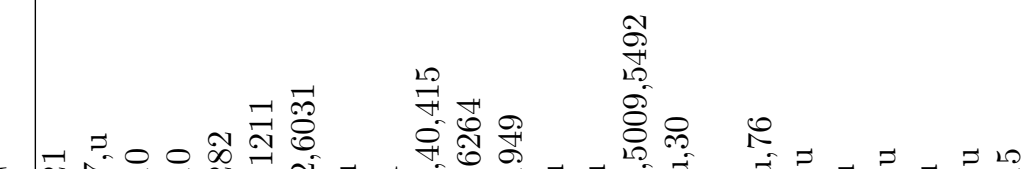

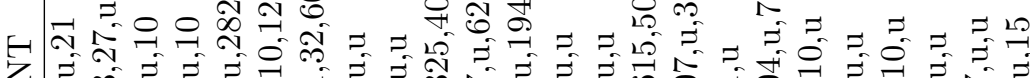

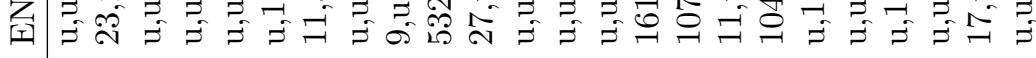

ฉ

$\dot{0} 0$ o 0 o 0 o

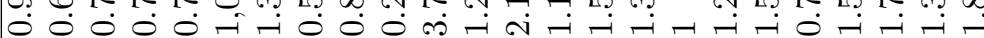

ర

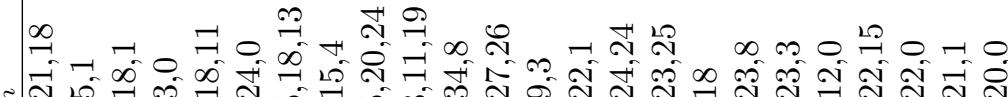

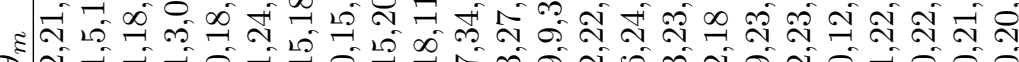

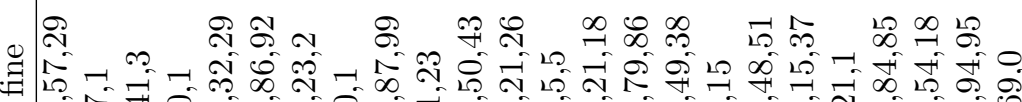

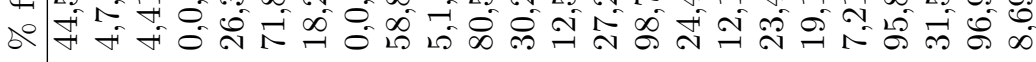

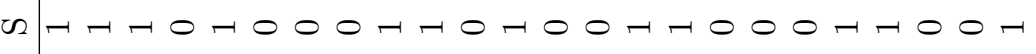

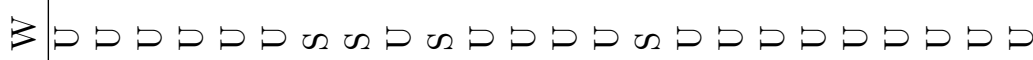

ค

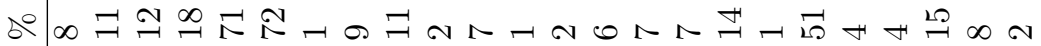

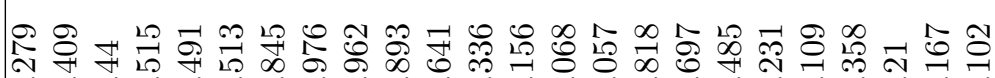

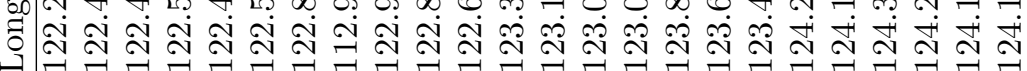

\&

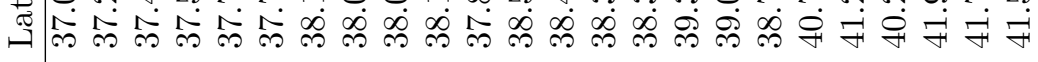

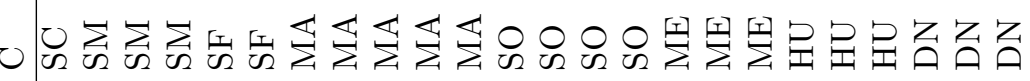

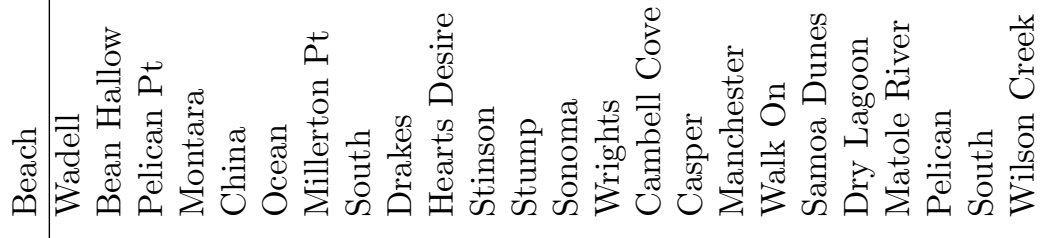

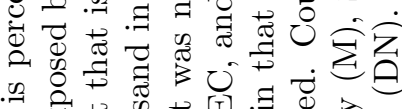

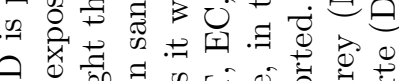

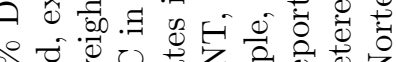

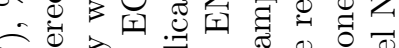

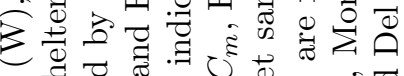
ช 可

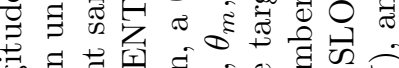

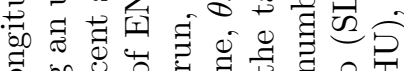
○

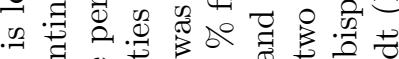

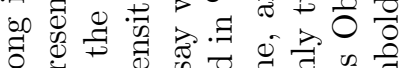

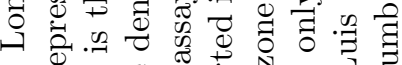

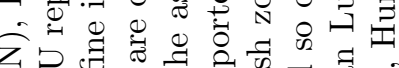

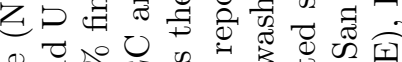
\&

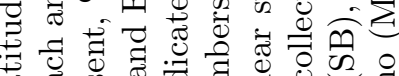

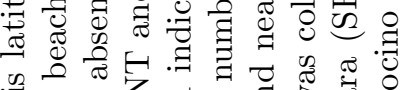

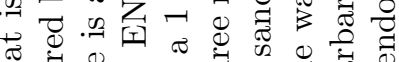

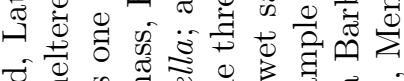
ठ 范

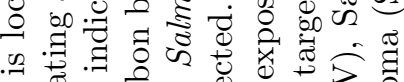

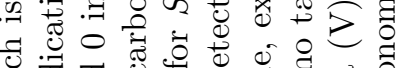

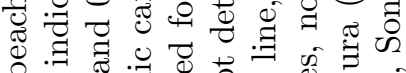

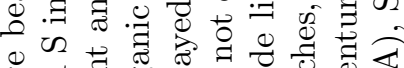
넘

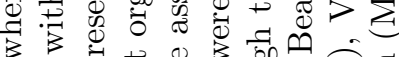
o

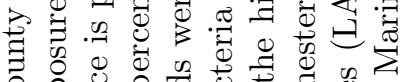
ठ

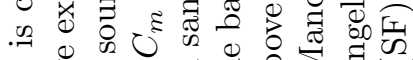

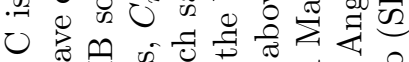

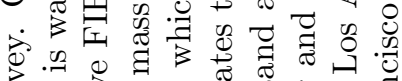

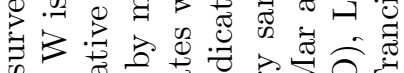

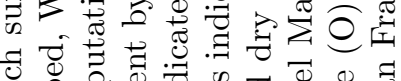
若

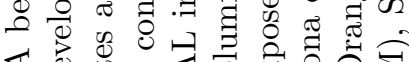

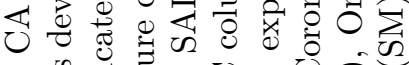

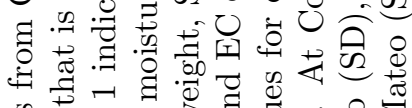

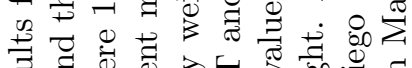

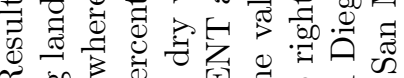

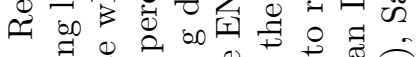

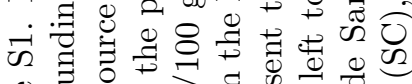

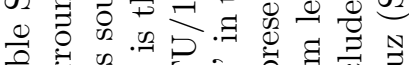

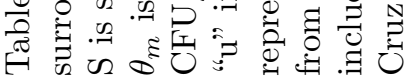




\begin{tabular}{|c|c|c|c|c|}
\hline Sample Description & Time & Tide & $\begin{array}{l}\text { ENT (CFU per } \\
100 \mathrm{~g} \text { or } 100 \mathrm{~mL})\end{array}$ & esp gene \\
\hline exposed sand $(21 \mathrm{~m})$ & $16: 40$ & flood & 1436 & - \\
\hline exposed sand $(20 \mathrm{~m})$ & $17: 00$ & flood & 251 & - \\
\hline exposed sand $(11 \mathrm{~m})$ & $21: 00$ & flood & 4452 & - \\
\hline submerged sand $(14 \mathrm{~m})$ & $21: 00$ & flood & 335 & + \\
\hline exposed sand $(10.5 \mathrm{~m})$ & $22: 00$ & ebb & 790 & + \\
\hline exposed sand $(11 \mathrm{~m})$ & $22: 40$ & $\mathrm{ebb}$ & 1251 & - \\
\hline exposed sand $(12 \mathrm{~m})$ & $23: 00$ & ebb & 4358 & - \\
\hline exposed sand $(13 \mathrm{~m})$ & 0:00 & ebb & 841 & - \\
\hline submerged sand $(31 \mathrm{~m})$ & 3:00 & ebb & 572 & - \\
\hline exposed sand $(30 \mathrm{~m})$ & $7: 20$ & flood & 2935 & + \\
\hline water & $19: 20$ & flood & 170 & - \\
\hline water & $21: 00$ & flood & 130 & - \\
\hline water & $21: 40$ & flood & 223 & - \\
\hline water & $22: 00$ & ebb & 170 & - \\
\hline water & $23: 00$ & ebb & 173 & + \\
\hline water & $23: 40$ & ebb & 133 & + \\
\hline water & $12: 00$ & flood & 100 & - \\
\hline sand near storm drain & n.a. & n.a. & 278 & + \\
\hline sand near storm drain & n.a. & n.a. & 567 & + \\
\hline storm drain effluent & n.a. & n.a. & 900 & + \\
\hline storm drain effluent & n.a. & n.a. & 393 & - \\
\hline
\end{tabular}

Table S2. Results from esp gene assay on LP samples. All samples were collected during the period 14:00 8 Aug 2006 and 14:00 9 Aug 2006. The distance from up-beach datum is reported for each sand sample in parentheses next to sample description. Water samples are of nearshore waters. + indicates the esp gene was detected. - denotes it was not detected. n.a. is not applicable. 


$\begin{array}{llll}r_{p} & \theta_{m} & C_{m} & \% \text { fine } \\ \theta_{m} & 1.0 & 0.33 & 0.33 \\ C_{m} & & 1.0 & 0.19 \\ \text { \% fine } & & & 1.0\end{array}$

Table S3. Pearson's correlation coefficients between various attributes of sand. All coefficients are significant at $p<0.05$ using the two-tailed test. 


\begin{tabular}{llcl} 
Sample Description & Date & HF marker & note \\
\hline \hline Nearshore water & 4 Mar 2007 & + & \\
\hline Storm drain effluent (1) & 4 Mar 2007 & + & \\
\hline Storm drain effluent (2) & 4 Mar 2007 & + & \\
\hline Sand near storm drain & 5 Feb 2007 & + & $\begin{array}{l}\text { DNAs from } 1 \text { g sand us- } \\
\text { ing soil kit }\end{array}$ \\
\hline $\begin{array}{l}\text { Sand from high tide line } \\
\text { S Feb 2007 }\end{array}$ & - & $\begin{array}{l}\text { DNAs from } 1 \text { g sand us- } \\
\text { ing soil kit }\end{array}$ \\
\hline $\begin{array}{l}\text { Composite of sand near } \\
\text { storm drain and sand } \\
\text { near high tide line }\end{array}$ & & - & DNAs from PBS eluant \\
\hline $\begin{array}{l}\text { Composite of two sand } \\
\text { samples from near high } \\
\text { tide line }\end{array}$ & & & \\
\hline
\end{tabular}

Table S4. + indicates the HF marker was detected. - denotes it was not detected. Notes indicate how the DNAs were extracted from sand samples. Storm drain effluent (1) and storm drain effluent (2) represent the two storm drain effluent samples. 


\section{$\frac{\mathrm{dN}}{\mathrm{dt}}=$ deposition + growth - removal - death $\mathrm{dt}$}

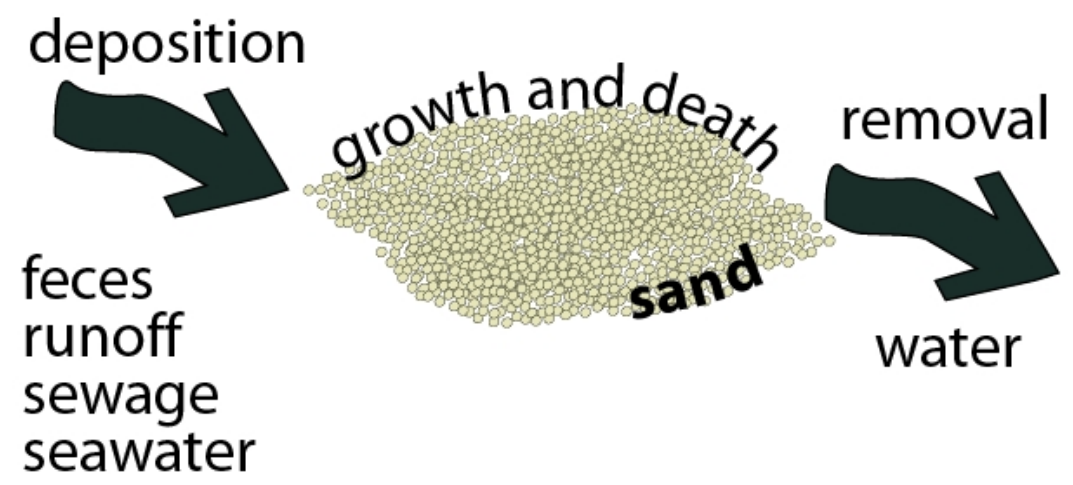

Figure S1. Number balance of fecal bacteria in a parcel of sand. Deposition might occur from factors listed on the left, growth and death may occur in sands, and removal may be mediated by water. In the equation, $N$ and $t$ represent the number of bacteria and time, respectively. 


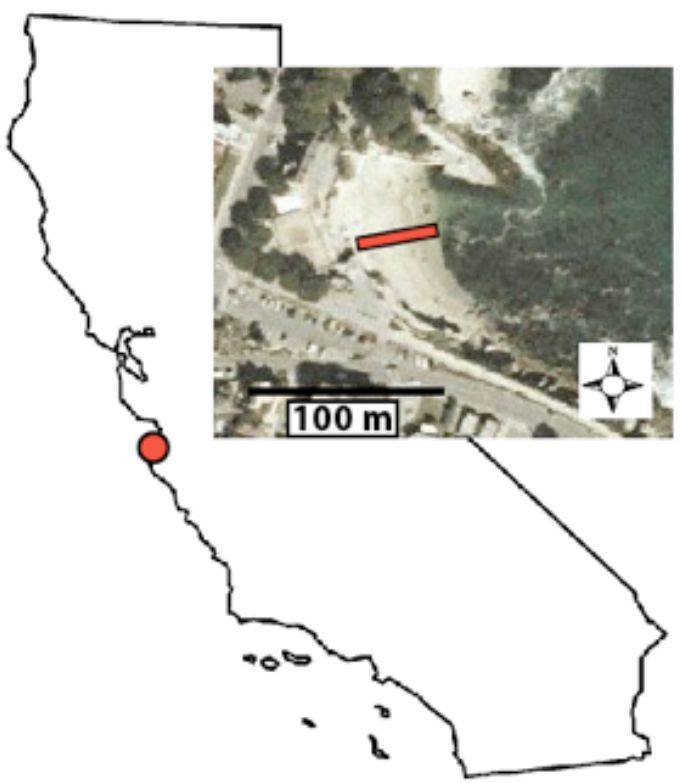

Figure S2. Location of Lovers Point located in Monterey County, CA. Transect where study was completed is shown in red. 


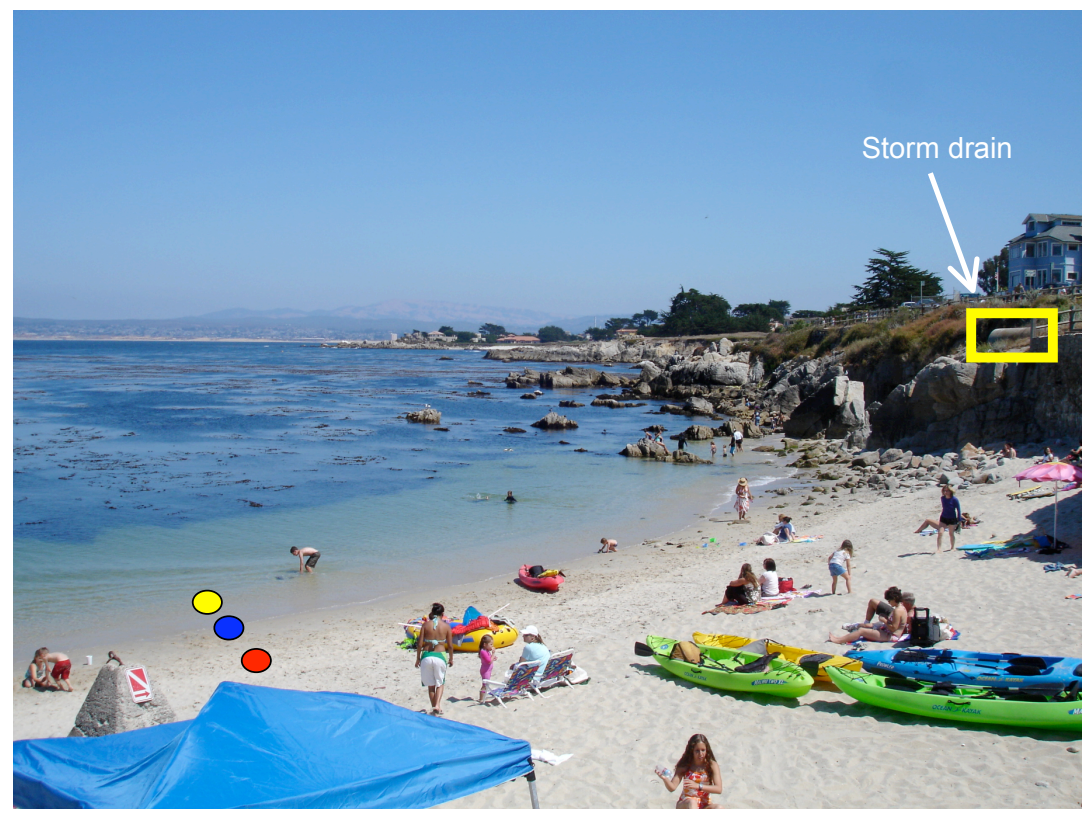

Figure S3. Photo of a portion of field site during the study. Exposed sand samples were collected $1.5 \mathrm{~m}$ landward of the waterline (red circle), submerged sand samples were collected $1.5 \mathrm{~m}$ seaward of the waterline (yellow circle), and an ankle depth water sample was collected (blue circle). The location of sampling changed as the tide rose and fell. The storm drain can be seen in the distance and is highlighted by a yellow box. 


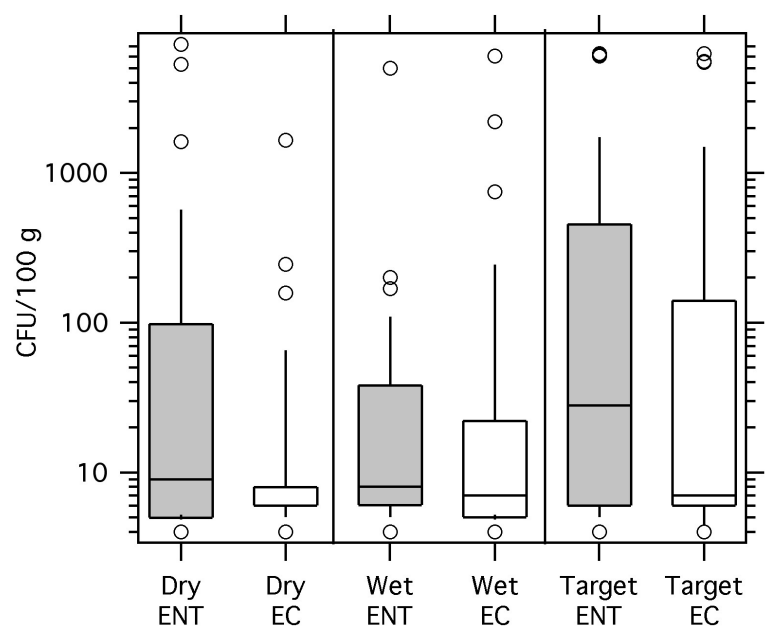

Figure S4. Box and whisker plots show the range of ENT and EC densities measured in different samples during the CA beach survey. Samples with densities below the detection limit were assigned a value of $50 \%$ the detection limit, as described in the text. Dry samples were collected above the high tide line, wet samples in the swash zone, and target samples from a river or random spot on the beach. The lower, middle, and top box edges correspond to the 25th, 50th, and 75th percentiles of the indicated distribution, the whiskers indicate the 10th and 90th percentiles, and the symbols show measurements lower and greater than the 5th and 95th percentiles, respectively. 


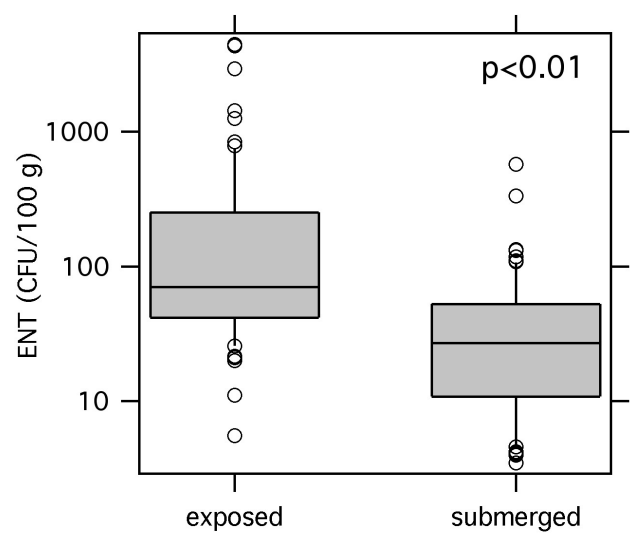

Figure S5. Box and whisker plots show the range of densities measured in exposed versus submerged sand at Lovers Point. The lower, middle, and top box edges correspond to the 25th, 50th, and 75th percentiles of the indicated distribution, the whiskers indicate the 10th and 90th percentiles, and the symbols show measurements lower and greater than the 5th and 95th percentiles, respectively. The two sets of measurements are significantly different $(p<0.01)$ based on the non-parametric Kruskal-Wallis test. 

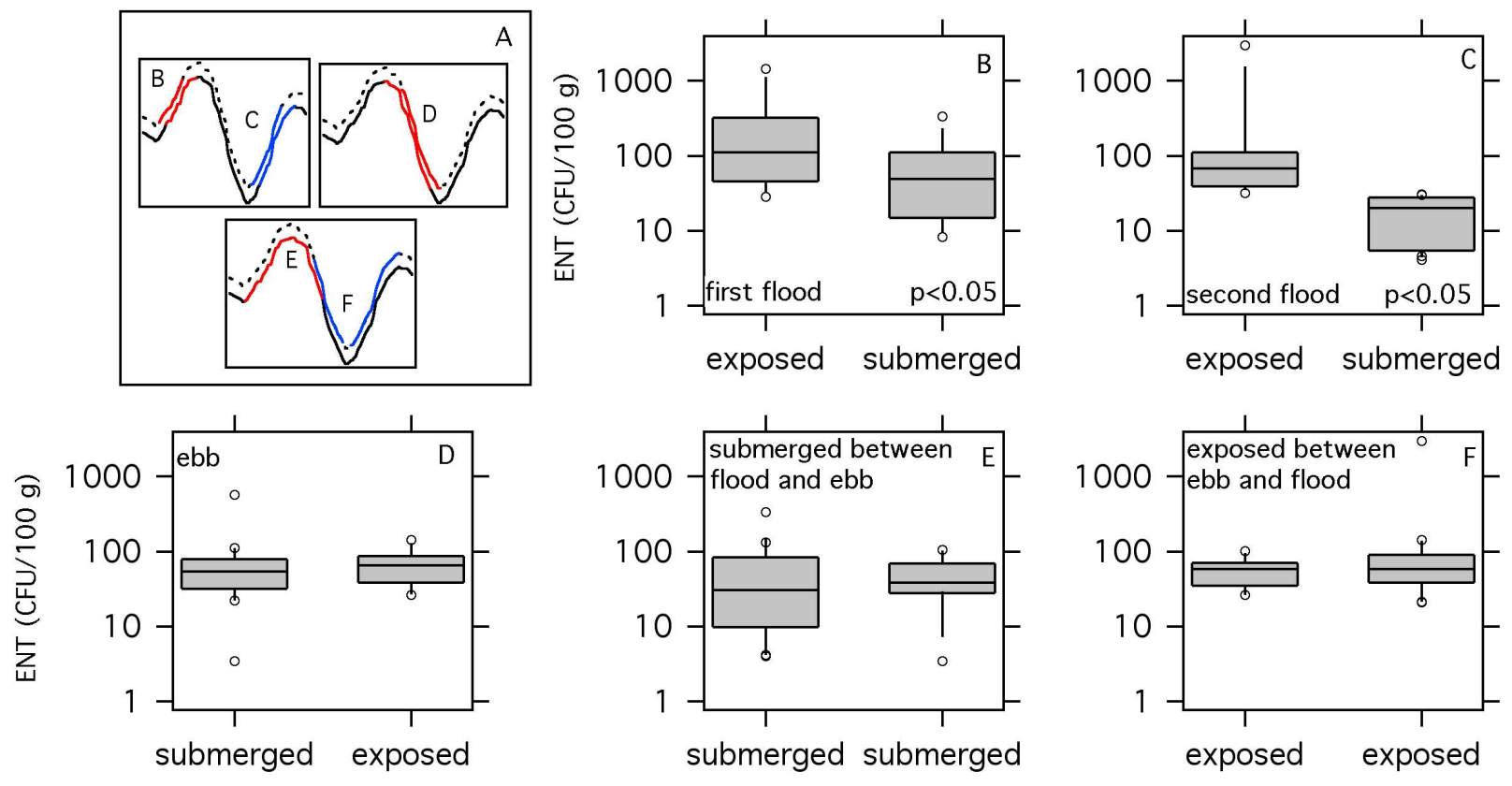

Figure S6. Box and whisker plots show the range of ENT densities measured in submerged and exposed sands measured at various times. The lower, middle, and top box edges correspond to the 25th, 50th, and 75th percentiles of the indicated set of measurements, the "whiskers" indicate the 10th and 90th percentiles, and the symbols show measurements lower and greater than the 5th and 95th percentiles, respectively. The curves in panel A are the location of exposed and submerged sand samples as a function of time (as shown in Fig. 3); the colored, labeled portions of the curves indicate the locations of compared measurements shown in panels B, C, D, E, and F. Panels B and C show that after exposed sands were submerged by the flood tide, ENT densities decreased significantly $(p<0.05)$. Panel D illustrates that as submerged sands becomes exposed during the ebb tide, there is no significant difference between ENT densities $(p=0.2602)$. There were no significant differences between consecutive measurements of ENT in submerged sands (Panel $\mathrm{E}, p=0.5292$ ), exposed sands (Panel F, $p=0.7555)$. 


\section{References}

[1] B. Malorny, J. Hoorfar, C. Bunge, and R. Helmuth. Multicenter validation of the analytical accuracy of Salmonella PCR: towards an international standard. Applied and Environmental Microbiology, 69:290296, 2003.

[2] T. A. Kettler, J. W. Doran, and T. L. Gilbert. Simplified method for soil and particle-size determination to accompany soil quality analyses. Soil Science Society of America Journal, 65:849-852, 2001.

[3] U.S. Environmental Protection Agency. Method 1600: membrane filter test method for enterococci in water. Technical report, Office of Water and Hazardous Materials, U.S. Environmental Protection Agency, Washington, D.C., 1997.

[4] T. M. Scott, T. M. Jenkins, J. Lukasik, and J. B. Rose. Potential use of a host associated molecular marker in Enterococcus faecium as an index of human fecal pollution. Environmental Science and Technology, 39:283 - 287, 2005.

[5] A. E. Santoro and A. B. Boehm. Frequent occurrence of the human-specific Bacteroides fecal marker at an open coast marine beach: Relationship to waves, tides, and traditional indicators. Environmental Microbiology, 2007. In press.

[6] A. B. Boehm, D. P. Keymer, and G. G. Shellenbarger. An analytical model of enterococci inactivation, grazing, and transport in the surf zone of a marine beach. Water Research, 39:3565-3578, 2005. 